\title{
PROCESSO DE TERRITORIALIZAÇÃO, COMUNIDADE TRADICIONAL E DESENVOLVIMENTO ECONÔMICO
}

Elisa Quint de Souza de Oliveira ${ }^{1}$ Isa de Oliveira Rocha ${ }^{2}$ Pedro Martins ${ }^{3}$

Resumo: O texto apresenta o contexto de formação e a conjuntura atual da luta da Comunidade dos Areais da Ribanceira (Imbituba, SC) pela sua continuidade histórica e manutenção da sua presença no território tradicional. Como referencial teórico considerou-se as ideias de territorialização do campo da geografia bem como os conceitos relacionados aos povos e comunidades tradicionais. Do ponto de vista metodológico o trabalho resulta de uma observação não sistemática e exploratória do agrupamento bem como do emprego de recursos documentais e revisão bibliográfica. Conclui-se que, no contexto da industrialização do sul de Santa Catarina, as dificuldades para garantir a continuidade da reprodução dos conhecimentos tradicionais apontam para a necessidade de resgate e manutenção do território e convivência no contexto mais amplo da reestruturação da zona portuária.

Palavras-chave: Comunidade tradicional. Territorialização. Desenvolvimento econômico. Imbituba/SC.

\section{TERRITORIALIZATION PROCESS, TRADITIONAL COMMUNITY AND ECONOMIC DEVELOPMENT}

Abstract: The text presents the context of formation and the current conjuncture of the struggle of the Areais da Ribanceira Community (Imbituba, SC) for its historical continuity and maintenance of its presence in the traditional territory. The theoretical framework considered the ideas of territorialization of the field of geography as well as concepts related to traditional peoples and communities. From the methodological point of view the work results from a non-systematic and exploratory observation of the cluster as well as the use of documentary resources and literature review. It is concluded that, in the context of the industrialization of southern Santa Catarina, the difficulties to ensure the continuity of the reproduction of traditional knowledge point to the need for rescue and maintenance of the territory and coexistence in the broader context of the port zone restructuring.

Keywords: Traditional community. Territorialization. Economic development.

\footnotetext{
1 Universidade do Estado de Santa Catarina (UDESC), Programa de Pós-Graduação em Planejamento Territorial e Desenvolvimento Socioambiental (PPGPlan), Florianópolis, Brasil, elisa21355@gmail.com, https://orcid.org/0000-0002-6493-131X

2 Universidade do Estado de Santa Catarina (UDESC), DeGeo/ Programa de Pós-Graduação em Planejamento Territorial e Desenvolvimento Socioambiental (PPGPlan), Florianópolis, Brasil, isa.rocha2007@gmail.com, https://orcid.org/0000-0001-9840-0595

3 Universidade do Estado de Santa Catarina (UDESC), Programa de Pós-Graduação em Planejamento Territorial e Desenvolvimento Socioambiental (PPGPlan), Florianópolis, Brasil, weltermartins@yahoo.com.br, https://orcid.org/0000-0002-7576-2830
} 


\section{PROCESO DE TERRITORIALIZACIÓN, COMUNIDAD TRADICIONAL Y DESARROLLO ECONÓMICO}

Resumen: El texto presenta el contexto de la formación y la coyuntura actual de la lucha de la Comunidad Areais da Ribanceira (Imbituba, SC) por su continuidad histórica y el mantenimiento de su presencia en el territorio tradicional. El marco teórico consideró las ideas de territorialización del campo de la geografía, así como los conceptos relacionados con los pueblos y comunidades tradicionales. Desde el punto de vista metodológico, el trabajo resulta de una observación no sistemática y exploratoria del clúster, así como del uso de recursos documentales y revisión de literatura. Se concluye que, en el contexto de la industrialización del sur de Santa Catarina, las dificultades para garantizar la continuidad de la reproducción del conocimiento tradicional apuntan a la necesidad de rescatar y mantener el territorio y la convivencia en el contexto más amplio de la reestructuración de la zona portuaria.

Palabras clave: Comunidad tradicional. Territorialización. Desarrollo económico.

\section{Introdução}

O texto que segue deriva de pesquisa mais ampla ${ }^{4}$ que objetivou compreender o processo de territorialização da comunidade Areais da Ribanceira município de Imbituba situando-a no contexto do desenvolvimento econômico do sul do Estado de Santa Catarina. A Comunidade Tradicional dos Areais da Ribanceira é formada por agricultores e agricultoras itinerantes, pescadores e pescadoras artesanais e extrativistas de butiá que fazem uso comum da terra inserida no complexo lagunar sul do Estado de Santa Catarina, distando aproximadamente 80 km de Florianópolis, capital do Estado.

A população tradicional enfocada na pesquisa original, que inspira as presentes reflexões, luta pelo direito de acesso à terra, aos seus recursos naturais, ao reconhecimento de suas formas de ocupação e ao direito de viver em consonância com os seus próprios valores, tradições e crenças. As atividades desenvolvidas pela comunidade asseguraram a subsistência das famílias até a década de 1970. Concomitantemente, na área urbana do município a população estava ligada às atividades portuárias e à indústria cerâmica. A apropriação do lugar para grandes projetos de desenvolvimento transformou as terras ocupadas, que eram públicas, em privadas, não obstante o fato da Constituição Federal de 1988 ter assegurado o direito das comunidades tradicionais ${ }^{5}$.

\footnotetext{
${ }^{4}$ A pesquisa mais ampla a que aqui se refere serviu de base para a realização da tese de Oliveira (2020).

${ }^{5}$ O Decreto Federal n. 6.040, de 07/02/2007, instituiu a Política Nacional de Desenvolvimento Sustentável dos Povos e Comunidades Tradicionais em consonância com a Convenção 169 da Organização Internacional do Trabalho, de 19/06/2002.
} 
Ocorre que o espaço tradicional do grupo vai além da área efetivamente ocupada em função da expropriação ocorrida nas últimas décadas. A maneira como uma forma espacial participa na produção do espaço, como afirma Santos (1999), não se dá apenas por meio de um procedimento natural. Há um conteúdo social que fornece ânimo ao espaço de modo que ele tenha determinado valor.

A região onde está localizada a Comunidade dos Areais da Ribanceira, próxima ao Porto de Imbituba, caracteriza-se pela atividade agrícola dividida em pequenas lavouras de uso tradicional, entremeadas por butiazeiros e outras espécies nativas. O porto, por sua vez, pelo escoamento da produção mineral a partir de Imbituba, possibilitou ao município desempenhar papel importante no desenvolvimento da indústria do carvão catarinense em razão de sua localização estratégica.

Figura 01 - Região enfocada dentro do Município de Imbituba

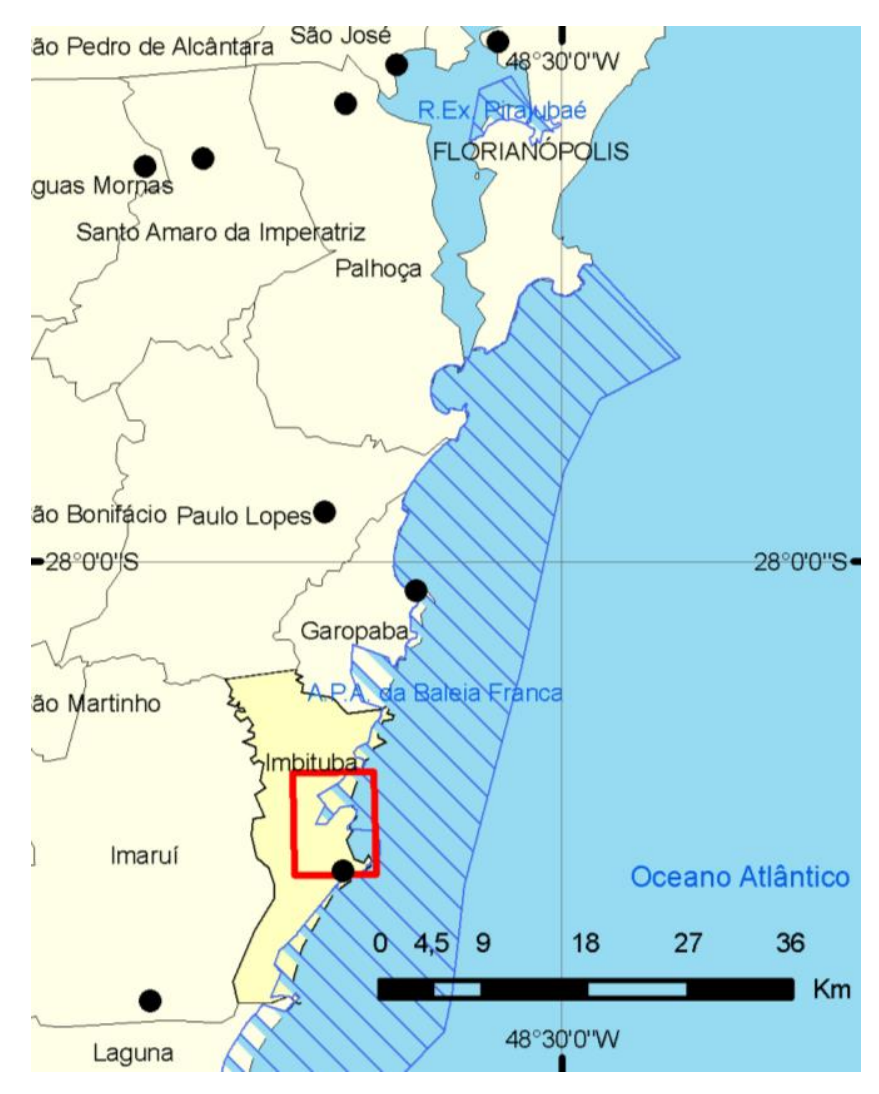

Fonte: NCS, 2011.

A agricultura e a pesca, no entanto, atividades desempenhadas desde a chegada dos primeiros ocupantes, sofreram e ainda sofrem as implicações de um desenvolvimento econômico que, embora tenha trazido prosperidade e importantes 
conquistas para o país, ignorou a conservação do saber/fazer local cujas peculiaridades presentes nas atividades desenvolvidas pelo grupo guardam riquezas materiais e simbólicas que o grupo e outros agentes externos tentam preservar.

No presente texto trata-se de abordar e refletir sobre o processo histórico e o contexto geral que afeta as populações atingidas sem, no entanto, entrar no detalhamento da territorialidade da população tradicional que motivou a pesquisa.

O tema abordado, portanto, integra uma longa linhagem de estudos enfocando comunidades tradicionais no Brasil como os inventariados por Almeida e Souza (2009), Acselrad (2010), Shiraishi Neto (2017); Grava, Florit e Antunes (2019) e Oliveira et al. (2020) mas também se insere no campo dos estudos sobre a ocupação e desenvolvimento do litoral catarinense, como em Cabral (1970), Zumblick (1987), Zanelatto (1992), Neu (2003), Pereira (2003) e Raimundo (2012).

Como referencial teórico, o estudo se orienta pelo conceito de território desenvolvido por Haesbaert (2016) - que também desenvolve a ideia de territorialização e desterritorialização, mostrando assim a dinâmica da territorialidade.

A ideia de territorialidade, por sua vez, conforme é compreendida por Little (2004) e amplamente empregada na produção bibliográfica recente, como em Marinho (2017), Santiago (2018), Sousa e Santos (2019), por exemplo, define o processo de luta da comunidade tradicional em questão mostrando como a ação política de mobilização e organização é a base da construção do território - ou da reterritorialização, no caso de um grupo esbulhado da terra.

O conceito de comunidade tradicional, conforme nosso entendimento, foi fixado na legislação brasileira pelo Decreto 6.040/2007 e, a partir daí, assimilado pela literatura especializada, como em Andrade (2008), Oliveira Filho (2011) e Martins (2020). Em seu artigo terceiro, o Decreto 6.040/2007 define como critério de inclusão na categoria de Povos e Comunidades Tradicionais o auto reconhecimento e o reconhecimento por outros da sua especificidade cultural e outros mecanismos de adscrição - no que é respaldado pela tradição antropológica resgatada por Barth (1998).

A metodologia utilizada como forma de abordagem do tema é a qualitativa baseada em pesquisa bibliográfica (Kerlinger, 1980), pesquisa documental (Bauer e Gaskell, 2018) e observação direta do recorte empírico (Minayo et al., 2001) e objetivou compreender o processo de territorialização (Haesbaert, 2016) da comunidade situando o município de Imbituba no contexto do desenvolvimento 
econômico do sul do Estado de Santa Catarina. Os acontecimentos históricos relevantes ligados às atividades econômicas desenvolvidas na região também foram levantados, além dos atores e as relações de força e poder que influenciaram na constituição do território.

A apresentação dos resultados está dividida em três partes, sendo que na primeira, "O processo de territorialização de Imbituba", trata-se de apresentar 0 processo histórico que desembocou nos acontecimentos analisados. Na segunda parte, "Recursos naturais e agentes econômicos", mostra-se como um recurso natural e uma iniciativa econômica garantiram o surgimento de um processo de exclusão retratado como puro empreendedorismo desenvolvimentista. Na terceira parte, "Populações tradicionais", trata-se de refletir sobre os impactos causados pela política desenvolvimentista mal conduzida sobre as populações tradicionais com ancestralidade e território nos Areais da Ribanceira.

\section{O processo de territorialização de Imbituba}

O processo que levou à ocupação atual de Imbituba iniciou no século XVII quando algumas famílias, por volta de 1675, vindas da localidade de Laguna, ${ }^{6}$ fixaram-se na região. A consolidação do povoamento, contudo, passa a ser observada somente a partir de 1715 com a fixação de algumas famílias de vicentistas em Imbituba. Poucos anos depois, a elas se somariam um grupo de casais portugueses vindos das Ilhas dos Açores e da Madeira (Zanelatto, 1992).

Os colonos açorianos e seus descendentes agregaram sua cultura ao ambiente natural ocupado e as freguesias, aos poucos, foram tomando forma e se constituindo em seu território. A exploração de produtos agrícolas, especialmente a farinha de mandioca, acompanhada da pesca, atividades ainda realizadas pela Comunidade dos Areais, consubstanciou a economia da população ${ }^{7}$. A realidade econômica de Imbituba, porém, sofreu forte mudança quando do estabelecimento da primeira armação baleeira pela administração portuguesa.

A Coroa portuguesa inseriu a caça da baleia na atividade econômica brasileira em 1602, no Estado da Bahia, mantendo-se constante até o Século XIX (Raimundo, 2012).

\footnotetext{
${ }^{6}$ Município localizado no litoral sul do Estado de Santa Catarina fundado em 1676 e palco de grandes acontecimentos de importância histórica nacional. É banhado por uma série de balneários e lagoas e possui um conjunto arquitetônico tombado pelo IPHAN (Instituto do Patrimônio Histórico e Artístico Nacional). Atualmente, é um dos pontos turísticos mais importantes do sul do Estado.

${ }^{7}$ Para dados sobre a população e o volume da economia no período ver Oliveira (2020).
} 
Vários pontos de caça e manufatura do óleo de baleia também foram implantados próximos aos povoados coloniais do litoral do Rio de Janeiro, de São Paulo e de Santa Catarina. As armações foram instaladas no intuito de legalizar e perenizar uma prática lucrativa.

Com a instalação do governo da Capitania em Santa Catarina surgiu o primeiro núcleo baleeiro com a implantação de seis $^{8}$ armações, sendo uma delas a Armação de Imbituba, localizada ao norte de Laguna, no distrito da freguesia de Sant'Ana de Vila Nova, local com condições favoráveis à atracação de barcos e à atividade baleeira, fundada em 1796. Segundo Raimundo

A Armação de Imbituba foi fundada por Pedro Quintela e João Ferreira Sola, os quais pagavam uma taxa de exploração à Coroa Real. Os lucros eram compensadores. Baleias de grande porte eram arpoadas quase semanalmente e rebocadas para os barracões, onde se procedia ao retalhamento e retirava-se a gordura para derreter em grandes caldeiras (2012, p. 68).

Ainda de acordo com essa autora, parte do azeite apurado tinha como utilidade o seu emprego na iluminação pública das grandes cidades existentes no país, a exemplo de Rio de Janeiro e São Paulo.

A Armação de Imbituba possuía edificações à beira mar e se localizava na praia do Porto (Zanelatto, 1992) que constituía um lugar capaz de comportar muitos ocupantes, com lagoas cheias de peixe e poucos habitantes na vila (Cabral, 1970).

A caça da baleia passou a ser uma das principais atividades econômicas em razão das demandas internas e externas pelo óleo do animal e foi, sem dúvida, a atividade que mais articulou economicamente o litoral e adicionou à estrutura econômica um grande número de escravos que representavam investimento de capital.

Os monopólios da Coroa portuguesa para a caça da baleia foram extintos em 1801 e a Armação de Imbituba, consequentemente, arrematada. Os novos exploradores registraram rendimentos reduzidos, fato relacionado, à época, à queda acentuada na quantidade de baleias capturadas devido à concorrência existente entre os empreendedores locais e os arpoadores estadunidenses e ingleses.

A chegada do petróleo, no século XIX, porém, influenciou sobremaneira a atividade pesqueira uma vez que antes da fabricação do querosene não havia concorrência para o óleo extraído das baleias. Os derivados do petróleo, por serem de origem mineral, menos onerosos e mais eficientes para a iluminação, dominaram

\footnotetext{
${ }^{8}$ Sendo elas, na llha de Santa Catarina: Piedade, por volta de 1740; Lagoinha, em 1772; Itapocoróia, em 1778; no litoral sul: Garopaba, por volta de 1793; Imbituba em 1796; e no norte a da llha da Graça, na entrada do canal de São Francisco, em 1780 (Raimundo, 2012).
} 
o produto animal o que, além de transformar o cotidiano dos trabalhadores, atingiu uma considerável parcela da população da vila de Imbituba.

Não obstante a caça da baleia ter se constituído a atividade econômica mais importante durante o período do funcionamento das armações, as atividades de subsistência realizadas pelas comunidades não se extinguiram. Foram essas mesmas atividades, ainda realizadas atualmente pelo grupo que vive nos Areais da Ribanceira, que permitiram a continuidade da vila de Imbituba mesmo após o fechamento da Armação Baleeira. Dessas atividades de subsistência originou-se um povoamento com descendentes de negros e portugueses que se tornou expressivo, mais adiante, na época das benfeitorias do porto.

$\mathrm{Na}$ época da colonização, quando inúmeros navios acostavam na enseada de Imbituba para o abastecimento de emergência, alguns navegadores já sabiam que essa área seria favorável, se realizados os melhoramentos necessários, para se tornar um grande porto. Neu (2003) afirma que, no "século XVI, alguns navegadores tinham conhecimento dessa área" (p.51) mas foi a caça da baleia, associada ao comércio de cabotagem, que tornou a enseada de Imbituba conhecida no restante do país.

No final do século XIX a descoberta do carvão na região sul do Estado de Santa Catarina propiciou o escoamento do mineral por meio da enseada de Imbituba quando as condições naturais se tornaram mais favoráveis. Neu (2003) faz referência ao momento da decadência da caça da baleia e à existência do porto:

O porto de Imbituba foi instalado na mesma enseada da armação baleeira. Durante quarenta anos aproximadamente as duas atividades conviveram juntas na Praia do Porto, mas viviam momentos distintos nos quais um estava em fase de decadência e 0 outro estava em ascensão (p. 35).

O transporte marítimo, porém, conhecido como o meio de transporte mais antigo e eficiente, somente se tornou viável economicamente com a diminuição de custos para a sua operação. A eficiência nas operações portuárias está ligada à qualidade dos equipamentos e serviços, o que garante o preço e a agilidade. Quando um porto apresenta tais características, com a infraestrutura necessária para atuar, ele deixa se ser um porto natural e passa a ser um porto organizado, o que ocorreu com o porto natural de Imbituba no início do século XX.

Foi a partir da descoberta do carvão e da construção da ferrovia, porém, que o porto de Imbituba se colocou no páreo para a disputa com o já conhecido porto de 
Laguna sobre qual deles se tornaria porto carbonífero - mesmo tendo os dois portos problemas para o desenvolvimento dessa indústria (Zumblick,1987). A enseada de Imbituba era aberta, o que não protegia os navios dos ventos, mas, em contrapartida, poderia receber navios de calados maiores. Laguna, no entanto, tinha um porto fechado, protegido dos ventos, mas possuía a barra escassa que não deixava passar navios com calado acima de dez pés. Os dois portos, portanto, necessitavam de benfeitorias para resguardar os navios com segurança, promovendo a passagem da produção de carvão.

Para que um sistema portuário seja considerado efetivamente implantado, são necessários muitos investimentos, uma boa administração e também preocupação com as questões de ordem prática. Segundo Neu (2003), o porto natural de Imbituba deu lugar, então, a "um porto capitalista e competitivo, deixando de lado uma visão poética dos portos naturais visitados por aventureiros e piratas" (p.51).

A área portuária, assim, foi delimitada pelo Governo Federal que determinou sua jurisdição, mas era necessário a continuidade de mais obras para que o empreendimento fosse transformado em um porto organizado. Somente em 1920 foi dado início a uma série de investimentos que operaram transformações importantes. A enseada de Imbituba passou a assumir a existência de um porto especializado no transporte de carvão, conquistando, inclusive, o status de porto brasileiro de maior cabotagem com a predominância da movimentação de embarque sobre o desembarque. Naquele ano de 1920 a Companhia Docas de Imbituba recebeu a concessão do porto e o administrou até 2012, realizando uma série de investimentos.

A história de ocupação do município de Imbituba e sua formação socioespacial, portanto, estão intimamente ligadas às armações baleeiras e também à atividade mineradora que marcou definitivamente a região - além, e sobretudo, da fixação de imigrantes que viriam a se constituir na população tradicional.

\section{Recursos naturais e agentes econômicos}

O povoado de Imbituba, por volta de 1870, com a descoberta das jazidas de carvão mineral, começou a sentir sinais de crescimento econômico. 0 desenvolvimento se deu, no entanto, de forma lenta em razão do carvão catarinense 
ter sido motivo de discussão quanto à sua qualidade e também pela dificuldade de seu transporte.

As dificuldades de transporte em Santa Catarina não permitiam uma vida econômica associada a outras regiões. Muito embora a caça da baleia tenha facilitado alguma integração ligando as armações com outros portos o seu fim levou à decadência econômica dos vilarejos. A necessidade de utilização da estrada de ferro para o escoamento da produção foi fator crucial na estagnação do Brasil no século XIX. Sobre a dificuldade do escoamento da produção, Bossle (1981) afirma:

As minas catarinenses possuíam a desvantagem de estarem afastadas dos portos que escoam o produto, dependendo da Estrada de Ferro Donna Thereza Christina para o transporte do carvão aos portos e, daí, aos mercados consumidores (p. 49).

A descontinuidade da exploração do carvão pelo Governo permitiu que a atividade fosse encampada pela iniciativa privada. A construção da estrada de ferro iniciou pela enseada de Imbituba partindo para a foz do rio Tubarão onde, atualmente, se encontra o Município de Criciúma.

A conjuntura econômica do litoral catarinense no início do século XX não era favorável, sobretudo, pela concorrência com a ampla produção agrícola das áreas coloniais de imigração europeia do interior e pela decadência da caça da baleia que havia perdido a sua importância econômica regional. O povoado que permanecia no local, cujos descendentes pertencem à Comunidade dos Areais da Ribanceira, adaptava-se à nova fase e permanecia realizando suas atividades de subsistência uma vez que o trabalho nas armações havia diminuído substancialmente.

A construção da estrada de ferro trouxe expectativas de desenvolvimento econômico à população. Em razão da pesca abundante, a agricultura era uma atividade secundária destacando-se alguns produtos como a farinha de mandioca ainda produzida pela comunidade tradicional em moldes semelhantes aos daquela época. O transporte da safra produzida era facilitado pela estrada de ferro sendo as vias fluviais também utilizadas para o transporte dos produtos.

O funcionamento da estrada de ferro, muito embora tenha sido concebido para o escoamento do carvão e, consequentemente, trazer lucros a quem explorava o mineral, influenciou sobremaneira a região auxiliando na expansão econômica do sul catarinense, na visibilidade das localidades de Imbituba e do Município de Laguna, além de trazer benefícios ao comércio local.

Ocorre que o escoamento da produção do carvão esbarrava no problema da barra da Laguna, que era o porto mais próximo, que não servia para o escoamento 
da produção em razão do seu baixo calado que o tornava inseguro para 0 atracamento dos navios de grande porte. Imbituba, porém, era a alternativa mais viável, mas carecia de obras que facilitassem a atracagem dos navios. Outro aspecto que dificultava o escoamento da produção era a tarifa de embarque de mercadorias, cuja porcentagem sobre o valor do produto obstava a competição com produtos estrangeiros.

As dificuldades que o Porto de Imbituba enfrentava para o carregamento do carvão eram muitas, havendo casos de navios que não conseguiam atracar em razão do mau tempo, outros que precisavam aguardar dias para poder desembarcar as cargas ou carregá-las. Além disso, o carvão não obteve a aceitação desejada uma vez que o preço mínimo de extração era alto e as impurezas contidas na carga eram muitas.

Não foi possível concorrer com o carvão importado da Inglaterra, com tantas dificuldades, o que culminou com o fracasso da exploração que cessou por completo no ano de 1884, levando a empresa mineradora à falência. Em 1902, a concessão da estrada de ferro foi resgatada pelo Governo Federal. A estrada, no entanto, continuou transportando mercadoria e passageiros não obstante as despesas fossem altas e a estrada não estivesse sendo utilizada com a total capacidade para a qual foi projetada (Melo, 1996).

Na seara legislativa o governo federal havia previsto a obrigação de consumo do carvão de origem estrangeira. Tentando incentivar a continuidade da estrada de ferro, no entanto, nos anos seguintes, o governo decidiu incentivar a exploração do carvão nacional e, por lei, criou medidas para isenção de taxas destinadas ao consumo próprio das companhias de navegação nacionais e estrangeiras, mas a situação econômica das minas ficou inalterada.

A empresa dos Lage, família de empreendedores que contribuiu sobremaneira com o desenvolvimento econômico do sul do Estado de Santa Catarina, importava o carvão cardiffss $^{9}$ inglês, desde a época de D. João VI no Brasil, além de realizar trabalhos de estiva. Após a exigência da nacionalização das empresas de navegação, advinda da Proclamação da República, a Lage \& Irmãos foi beneficiada e ampliou seus negócios.

A negociação com as terras carboníferas no Estado de Santa Catarina, portanto, significava um investimento para abastecer os navios da sua própria frota e o estaleiro que detinham na llha Viana, no Rio de Janeiro. Mesmo diante das más

\footnotetext{
${ }^{9}$ Carvão inglês com grande capacidade para queima e muito utilizado como combustível.
} 
condições de escoamento da produção de carvão, a empresa apostou em um investimento de longo prazo com a compra das terras.

Henrique Lage e mais dois irmãos esperavam a ocasião favorável para a exploração do carvão nas terras herdadas pelo pai, Antônio Lage, mas com o início da $1^{\text {a }}$ Guerra Mundial (1914 a 1918) os navios da empresa familiar ficaram sem combustível e a companhia Lage \& Irmãos precisou iniciar os trabalhos de pesquisa e exploração das minas de carvão.

A queda nas exportações nesse período diminuiu sobremaneira a arrecadação do Governo Federal que incentivou a produção, em geral, uma vez que grande parte dos impostos arrecadados era originária da exportação, configurando a exploração do carvão uma saída viável para auxiliar o desenvolvimento. Mamigonian (1966) faz referência a esse período:

O Sul de Santa Catarina passou por radical transformação com o advento da Primeira Guerra Mundial: empresas brasileiras consumidoras de carvão (navegação, iluminação a gás) se viram forçadas, na falta de carvão estrangeiro, a iniciar a extração de carvão nacional. Os anos que se seguiram foram difíceis, mas as leis governamentais estimulando o consumo do carvão nacional (1931 a 1937) e a segunda guerra mundial garantiram a sobrevivência e expansão da economia carbonífera nacional (p.36).

Aproveitando os incentivos que o Governo Federal havia concedido para a produção da indústria de base, a empresa de Henrique Lage deu início aos investimentos no Sul de Santa Catarina com a realização de pesquisas que chegaram a resultados positivos. Belolli et al.(2002) fazem referência ao período:

Superar as dificuldades brasileiras, diante da expansão do conflito mundial, aos homens do Governo não pareceu restarem outras alternativas, senão se voltarem à exploração de nossas riquezas naturais, como a do carvão mineral, embora tivessem que superar as críticas de seu uso (p.113).

Mamigonian (1986) ainda discorre sobre as consequências da 1a Guerra mundial para o desenvolvimento da região sul catarinense:

A conjuntura da Primeira Guerra Mundial foi muito favorável a [industrialização catarinense] [...] e deu oportunidade ao surgimento da produção carbonífera em Santa Catarina e no Rio Grande do Sul. Os grandes armadores do Rio de Janeiro como Henrique Lage, ficaram muito vulneráveis à queda das importações do carvão-vapor europeu necessário às caldeiras de seus navios, e assim investiram maciçamente na abertura de minas, iniciando-se em 1917 produção comercial (p.104). 
Primeiramente, a empresa de Henrique Lage realizou a compra de equipamentos para a lavagem do carvão permitindo seu melhor aproveitamento e depois realizou melhoramentos na estrada de ferro, como a construção de ramais até as minas exploradas pela firma Lage \& Irmãos. A empresa também se beneficiou de normas governamentais que autorizavam o Governo a conceder empréstimos às companhias que lavrassem minas de carvão e promovessem a construção de ramais de estrada de ferro que eram indispensáveis ao transporte e escoação da produção. Sobre essa fase, Bossle (1981) relata:

Necessariamente, a empresa teria que dar início à exploração do carvão em Santa Catarina, formando companhias de mineração, como: a Companhia Nacional de Mineração de Carvão do Barro Branco, incorporação da Companhia Brasileira Carbonífera Araranguá; Companhia Docas de Imbituba e mais atividades periféricas, como o Banco Sul do Brasil e a Companhia de Navegação São João da Barra e Campos. A formação dessas companhias dependia de créditos governamentais e de um mercado interno (p. 31).

A Estrada de Ferro Teresa Cristina, que havia voltado à administração pública, foi concedida para o grupo que controlava a Companhia Brasileira Carbonífera de Araranguá (C.B.C.A.) e que pertencia ao grupo de Henrique Lage desde 1917, permitindo que, a partir de 1918, as empresas Lage \& Irmãos controlassem também o transporte da ferrovia (Neu, 2003).

Para solucionar a questão da mão de obra Henrique Lage criou vilas operárias, inclusive com uso de água tratada e energia elétrica, casas para administradores, oficinas mecânicas, olarias, marcenarias e outras atividades que compõem uma cidade. A Vila de Imbituba cresceu, assim, tendo seu funcionamento e contendo serviços comparáveis às grandes cidades. Vale referir que todo empenho foi realizado em razão da exploração e em benefício do aumento significativo do patrimônio privado. Não há na literatura qualquer menção à proteção das formas de uso da terra pelos primeiros habitantes de Imbituba. Toda a localidade servia ao industriário e seus negócios e chamava cada vez mais habitantes em busca de trabalho. A atenção governamental, no entanto, sempre esteve voltada à proteção dos interesses privados do capital.

Sobre a origem dos operários que vinham para Imbituba em busca de trabalho, afirma Mamigonian:

A industrialização das áreas alemãs e do sul de Santa Catarina atraiu população luso-brasileira das vizinhanças. Assim, a maior parte dos mineiros de carvão são de origem açoriana-madeirense do 
litoral sul e importante parcela do operariado de Blumenau, Joinville, Brusque, [...] constituiu-se igualmente de luso-brasileiros das áreas próximas de cultura decadente (1966, p.36).

A diferença entre o melhoramento dos Portos de Imbituba e Laguna, que permitia o favorecimento de Imbituba por Henrique Lage, era que muitos dos terrenos de marinha existentes pertenciam ao grupo de sua empresa. As áreas próximas ao Porto haviam sido compradas do Visconde de Barbacena por Antônio Lage ainda em 1887 (Bossle, 1981). Assim, não obstante a ausência de autorização legal do Governo Federal, Henrique Lage iniciou a realização de alguns melhoramentos para escoamento da produção de carvão. A população existente na época, vizinha ao Porto, sentiu fortemente as transformações ocorridas.

Em 1919, desse modo, teve início a construção de uma fábrica de cerâmica, de grande porte, contando inclusive com equipamentos italianos destinados a facilitar o processo produtivo que objetivava produzir louças destinadas aos navios do Grupo Lage com o aproveitamento de matéria-prima, o barro branco, extraída das minas de carvão.

A presença da fábrica atraiu trabalhadores de variadas localidades, até mesmo italianos de Tubarão que vieram para a bem-sucedida Vila. O Porto já era conhecido como porto organizado e o desenvolvimento acelerou a ponto da emancipação política ocorrer poucos anos depois, em 1923. O Governador Hercílio Luz concedeu oficialmente a instalação do município em $1^{\circ}$ de Janeiro de 1924 , quando ocorreu a posse do primeiro Prefeito, Álvaro Catão, engenheiro de confiança de Henrique Lage que, com a morte deste último, em 1942, tornou-se proprietário do Porto e dos investimentos do Sul (Neu, 2003).

O sul do Estado de Santa Catarina, portanto, se transformou no período da primeira guerra mundial quando as empresas brasileiras que consumiam carvão importado tiveram que iniciar a extração de carvão nacional. Com estímulos normativos e o advento da segunda guerra mundial o consumo do minério brasileiro garantiu a expansão da economia carbonífera nacional.

\section{Populações tradicionais}

A cidade de Imbituba cresceu e se desenvolveu para atender aos interesses das atividades portuárias sem qualquer preocupação preservacionista, tanto ambiental quanto cultural. A partir de 1958, data da segunda emancipação, até finais 
da década de 1980 a economia de Santa Catarina viveu o período mais abundante da exploração do carvão - que era chamado "ouro negro" do Sul do Estado.

As minas existentes foram exploradas por mineradores do Rio de Janeiro e também por descendentes de imigrantes italianos. O progresso da região atraiu mão-de-obra contribuindo assim para o rápido crescimento populacional e econômico.

Os problemas econômicos mundiais serviram para impulsionar a utilização do carvão nacional e criaram infraestruturas capazes de designar um novo período da história. Porém, a atividade extrativa do carvão catarinense sofreu com a concorrência do mineral inglês uma vez que a extração e o frete eram mais baratos.

Os incentivos do Governo Federal para o consumo do carvão nacional, no entanto, impulsionaram o desenvolvimento com reflexos para toda a região. Os incentivos, todavia, ocorriam em momentos de crise internacional, ocasião em que a economia brasileira, da mesma forma, precisava de auxílio para continuar crescendo.

Nesse período, décadas de 1950 a 1980, a área de influência do Porto de Imbituba passa a atender mercados de cidades maiores e mais importantes para o país, como Rio de Janeiro e São Paulo. A importação inicia com as cidades vizinhas de Imbituba sendo atendidas com produtos vindos dessas grandes cidades.

Assim, a hinterlândia do Porto de Imbituba, área onde se encontra a Comunidade dos Areais da Ribanceira, estendia a sua área de alcance e intensificava a produção local, muito embora o objetivo fosse apenas organizar o porto para escoar a produção do carvão. A realidade do incremento da produção local, porém, estimulava o aumento da capacidade portuária e proporcionava a elaboração de projetos de ampliação das instalações existentes, o que comprometia a permanência dos ocupantes que ainda viviam da pesca artesanal e da agricultura itinerante na região.

A cidade de Imbituba, portanto, se desenvolveu como uma extensão do Porto já que a atividade ali realizada impunha a presença de muitos serviços que até então não existiam. Isso atraiu trabalhadores e comerciantes das cidades próximas interessados em investimentos no local como a construção de armazéns para a comercialização de produtos agrícolas da região com mercados de outras cidades brasileiras e alguns países europeus.

A formação da hinterlândia do Porto começou, portanto, após a década de 1960 com uma fase de prevalência das primeiras organizações, compreendendo a 
organização do Porto e resolvendo as questões naturais que limitavam a chegada dos navios. Ao longo dos anos as medidas de amparo implementadas pelo Governo Federal se intensificaram culminando com parcerias realizadas que objetivaram a ampliação das obras do Porto.

A partir da década de 1960, as cargas movimentadas, além da farinha de mandioca e seus derivados, eram diversificadas em razão da intensificação das exportações. Nessa época, os navios da frota de Henrique Lage foram substituídos pela frota da Companhia Siderúrgica Nacional, criando um longo monopólio de navegação estatal, mas a movimentação de longo curso não era contínua no Porto. A importação ou exportação dependia das oscilações do mercado.

No cenário estadual, o Governo de Santa Catarina implantava o Plano Diretor de Desenvolvimento Integrado de Imbituba - PDDI. Em razão do Plano, o Estado declarou de utilidade pública áreas que deveriam ser desapropriadas para servir à instalação do complexo industrial, à urbanização e ao sistema viário. Essas áreas compreendiam parte das terras ocupadas pela Comunidade dos Areais - que vê começar assim o seu processo de desterritorialização.

Nesse ínterim, foi criada a Companhia de Distritos Industriais de Santa Catarina - CODISC que efetuaria as desapropriações e coordenaria o trabalho com as terras na região, visando atender ao Plano Diretor de Desenvolvimento Integrado - PDDI. O início dos processos de desapropriação das terras constituiu o primeiro passo para a desterritorialização das famílias da Comunidade dos Areais da Ribanceira que, sem documentos que comprovassem propriedade ou posse, foram forçadas a sair da área deixando para trás moradias e os cultivos de subsistência.

$\mathrm{Na}$ medida em que a CODISC tomava conta das terras, porém, começava também a vendê-las, tornando-as terras particulares, o que deu início ao processo de privatização. Ao mesmo tempo em que o espaço público era tomado o município transformava a cidade em distrito industrial onde deveriam ser instaladas diversas indústrias que atendessem à demanda do complexo industrial. A Indústria Carbonífera Catarinense - ICC foi a única empresa que se instalou e proporcionou modificações no Porto construindo mais infraestrutura que possibilitou atender às suas próprias necessidades.

Naturalmente, diante do processo de desterritorialização muitas famílias foram desalojadas, não obstante os valores pagos pelas indenizações tenham sido insuficientes. A necessidade de moradia dessas famílias desalojadas impulsionou o surgimento de loteamentos irregulares no entorno da área do Porto. A promessa do 
poder público à época era a da criação de numerosas vagas de empregos geradas pelo complexo industrial - o que não foi concretizado fazendo permanecer as famílias em condições precárias.

Outro fator importante a ressaltar foi a ampliação do sistema de transporte, sobretudo o término das obras da BR 101, sendo a década de 1980 época em que as cargas eram tão grandes que, por vezes, eram recusadas representando a maior movimentação da história. Essa movimentação nos primeiros anos da década coincidiu com a crise do petróleo favorecendo o transporte do carvão com a redução significativa dos custos. Em seguida, a produção carbonífera entrou em crise, conforme observa Goularti:

A crise no setor carbonífero, que já vinha sendo anunciada desde 1986, pode ser visualizada na queda acentuada da produção e oferta de empregos. Em 1989, foram extraídos 13,9 milhões de toneladas de ROM, volume que em 1991 caiu para 6,7 milhões e a oferta de emprego caiu de 7,9 mil para 4,4 mil, respectivamente (2002, p.344).

Com a extinção dos subsídios, houve a diminuição da movimentação do porto e a ausência de uma política de diversificação para o enfrentamento da crise demonstrava a dependência de Imbituba em relação à economia carbonífera, uma vez que envolvia o sistema de mineração, a ferrovia, o porto e a Indústria Carboquímica Catarinense.

As alterações nas movimentações de carga no início dos anos 1990 demonstram a procura de soluções para o Porto. Para que a hinterlândia fosse ampliada era preciso que a zona portuária se transformasse atraindo indústrias e facilitando a obtenção de cargas. Vale afirmar que a hinterlândia portuária de Imbituba, historicamente, sempre foi influenciada pelas decisões governamentais que procuravam atender prioritariamente aos interesses econômicos hegemônicos da época.

O Porto de Imbituba, portanto, passou por diversos momentos, funcionando em razão de um produto principal que era o carvão. Os outros produtos eram carregados mediante a disponibilidade do Porto. As possibilidades para que o Porto de Imbituba vencesse a concorrência, portanto, decorriam da execução de amplos projetos de infraestrutura e as obras realizadas não eram suficientes. Em 1993 ocorreu o fim do transporte de carvão por meio do Porto de Imbituba.

Com a intenção de preservação do seu modo de vida e das práticas de manejo específicas, além do uso comum das terras, no ano 2000 os integrantes da 
Comunidade dos Areais da Ribanceira se organizaram para a criação da Associação Comunitária Rural de Imbituba - ACORDI. Desde então a associação busca, junto a várias instituições, mecanismos de regularização e proteção ambiental das áreas de terra daquela região.

As iniciativas de defesa dos direitos da Comunidade foram muitas, inclusive, com propostas de criação de unidades de conservação como Reserva Extrativista, Reserva de Desenvolvimento Sustentável ou Assentamento Rural, cujos procedimentos se arrastam sem qualquer solução (Mombelli, 2013).

A partir de 2010, ocorreu o desenvolvimento da Nova Cartografia social dos povos e comunidades tradicionais do Brasil (Varella et al., 2013) e potencializaramse os processos de mobilização do grupo e sua luta pelos mecanismos legais no intuito de assegurar o reconhecimento do seu território tradicionalmente ocupado. No caso dos Areais da Ribanceira, os registros de diferentes relatos evidenciaram experiências históricas continuadas de expropriação de terras utilizadas em comum há mais de um século, como se pode verificar em Oliveira (2020).

Em 2012 o Governo do Estado de Santa Catarina assumiu a administração do Porto, por meio da SCPar, cuja concessão pertencia à Companhia Docas desde 1941. Ainda que o Estado tenha assumido a administração do Porto, a luta da Comunidade dos Areais da Ribanceira permanece, uma vez que a intenção da SCPar é colocar em prática projetos de melhoramentos da hinterlândia portuária e do próprio Porto cujas modificações interferem diretamente na área que corresponde aos ranchos de pesca da Comunidade.

Frente ao processo descrito, resta-nos compartilhar o assombro da população tradicional dos Areais da Ribanceira diante da ostensiva atuação do Estado na defesa e na proteção dos interesses econômicos dominantes que redundam em descaso, violência e no seu abandono. A continuidade da sua reprodução material e dos conhecimentos tradicionais apontam para a necessidade de resgate $e$ manutenção do território e a garantia da convivência no contexto mais amplo da reestruturação da zona portuária.

\section{Considerações finais}

Desde o período dos primeiros ocupantes, não obstante todas as crises vividas - desde a primeira armação baleeira, a organização do porto e o período carbonífero - no litoral de Imbituba sempre estiveram presentes habitantes que, 
embora invisíveis ou irrelevantes (do ponto de vista do poder público) diante do cenário econômico imposto, manejavam a biodiversidade existente, plantavam e supriam suas necessidades básicas por meio da pesca artesanal - consistindo estes elementos os principais indicadores da sua territorialidade.

Nas crises econômicas ocorridas havia o fortalecimento dos conhecimentos comuns e os modos de vida da comunidade local no uso da terra, na pesca e no manejo de espécies nativas que permearam toda a história de desenvolvimento de Imbituba e região e fizeram com que áreas importantes da biodiversidade local fossem preservadas.

A privatização de terras tradicionais impulsionada pelo mito do progresso que culminou na desterritorialização e na tentativa de resistência da Comunidade possui ligação direta com toda a trajetória do Porto de Imbituba e a área portuária planejada para expansão e instalação de grandes empresas.

A história de ocupação do município de Imbituba e sua formação social, portanto, esteve intimamente ligada às armações baleeiras e à atividade mineradora que passou por períodos de crescimento e momentos de crise, como a primeira e a segunda guerras mundiais, a crise dos anos 1930 e a crise do petróleo - mas também às populações tradicionais que lá se reproduziram e construíram um modo de vida que constitui hoje um patrimônio imaterial.

É possível perceber que as crises, tanto internacionais quanto nacionais, foram momentos de crescimento na região. Porém, o processo de territorialização da comunidade também se fortaleceu a cada crise com o uso das terras em comum e a subsistência da população local mediante as atividades de pesca, plantio e manejo dos recursos naturais efetivados pelo grupo, apesar de todo esforço realizado pelo poder público para atender aos interesses econômicos ligados à hinterlândia portuária.

\section{REFERÊNCIAS}

ALMEIDA, Alfredo Wagner Berno de; SOUZA, Roberto Martins de. (orgs.). Terras de faxinais. Manaus: Edições da UEA, 2009.

ACSELRAD, Henri. Cartografia social e dinâmicas territoriais: marcos para o debate. Rio de Janeiro: UFRJ/IPPUR, 2010.

ANDRADE, Maristela de Paula. Terra de índio - identidade étnica e conflito em terras de uso comum. 2 ed. São Luis: EdUFMA, 2008. 
BARTH, Fredrick. Grupos étnicos e suas fronteiras. In: POUTIGNAT, Philippe; STREIFF-FENART, Jocelyne. Teorias da etnicidade. São Paulo: Editora da Unesp, 1998, p. 185-227.

BAUER, Martin W.; GASKELL, George. Pesquisa qualitativa com texto, imagem e som. 13 ed., 3 reimp. Petrópolis: Vozes, 2018.

BELOLLI, Mário; QUADROS, Joice; GUIDI, Ayser. História do carvão de Santa Catarina. Florianópolis: IOESC, 2002.

BOSSLE, Ondina Pereira. Henrique Lage e o desenvolvimento sul catarinense. Florianópolis: Editora da UFSC, 1981.

CABRAL, Oswaldo. História de Santa Catarina. Rio de Janeiro: Laudes, 1970.

GOULARTI FILHO, Alcides. Formação econômica de Santa Catarina. Florianópolis: Cidade Futura, 2002.

GRAVA, Diego da Silva; FLORIT, Luciano; ANTUNES, Douglas Ladik. Cipozeiras e cipozeiros da Mata Atlântica e conflitos ambientais territoriais em Santa Catarina. Novos cadernos NAEA, v. 22, n. 2, p. 69-92, mai./ago. 2019.

HAESBAERT, Rogério. O mito da desterritorialização. 10 ed. Rio de Janeiro: Bertrand Brasil, 2016.

KERLINGER, Fred N. Metodologia da pesquisa em ciências sociais. São Paulo: EPU, 1980.

LITTLE, Paul E. Territórios e povos tradicionais no Brasil: por uma antropologia da territorialidade. In: Anuário antropológico 2002-2003. Rio de Janeiro: Tempo Brasileiro, 2004, p. 251-290.

MAMIGONIAN, Armen. Vida regional em Santa Catarina. Revista Orientação, São Paulo, n², p.35-38, 1966.

MAMIGONIAN, Armen. Indústria. In: SANTA CATARINA. GAPLAN. Atlas de Santa Catarina. Rio de Janeiro: Aerofoto Cruzeiro, 1986, p. 104-106.

MARINHO, Thais Alves. Territorialidade e cultura entre os Kalunga: para a lém do culturalismo. Caderno CRH, Salvador, v. 30, n. 80, p. 353-370, 2017.

MARTINS, Pedro. Messiânicos \& Bandoleiros. Curitiba: Brazil Publishing, 2020.

MELO, Josemir Camilo. O papel dos investimentos ferroviários ingleses no Nordeste, 1852-1902 (nota para um estudo da história ferroviária). Sitientibus, Feira de Santana, no 15, p. 363-388, 1996.

MINAYO, Maria Cecília de Souza (org.). Pesquisa social. Teoria, método e criatividade. 18 ed. Petrópolis: Vozes, 2001.

MOMBELLI, Raquel. Comunidade Tradicional dos Areais da Ribanceira. Imbituba (SC): desenvolvimento, territorialidade e construção de direitos. Revista Estudos Sociológicos, Araraquara: v. 18, n. 35, p. 325-345, 2013.

NCS - NOVA CARTOGRAFIA SOCIAL DOS POVOS E COMUNIDADES TRADICIONAIS DO BRASIL: Comunidade Tradicional dos Agricultores e Pescadores dos Areais da Ribanceira. Manaus: Projeto Nova Cartografia Social da Amazônia/ UEA Edições, 2011.

NEU, Márcia Fernandes Rosa. Porto de Imbituba: de armação baleeira a porto carbonífero. Tubarão: UNISUL, 2003. 
OLIVEIRA, Elisa Quint de Souza de. Desterritorialização e resistência nos Areais da Ribanceira: a busca de uma comunidade tradicional pelo direito a terra em Imbituba-SC. Tese de doutorado - PPGPLAN/UDESC. Florianópolis, 2020.

OLIVEIRA, Elisa Quint de Souza de; MARTINS, Pedro; ANTUNES, Douglas Ladik. Areais da Ribanceira: comunidade tradicional e território em Imbituba/SC. Revista Brasileira de Desenvolvimento Regional, Blumenau, n; 8, v. 1, p. 175-194, 2020.

OLIVEIRA FILHO, João Pacheco de. A Presença Indígena no Nordeste: processos de territorialização, modos de reconhecimento e regimes de memória. Rio de Janeiro: Contra Capa, 2011.

PEREIRA, Raquel Maria Fontes do Amaral. Formação sócio-espacial do litoral de Santa Catarina: gênese e transformações recentes, Geosul, Florianópolis, v. 18, n. 35, p. 98-129, 2003.

RAIMUNDO, Maria da Conceição Moreira Barreto. Vila de Imbituba: do progresso à modernidade e espaço de exclusão. Veredas da História, ano 5, edição 2, p. 64-76, 2012.

SANTIGO, Cristina de Marco. Territorialidade de sitiantes tradicionais no estado de São Paulo. Mercator, Fortaleza, v. 17, p. 1-20, 2018.

SANTOS, Milton. A natureza do espaço: técnica e tempo, razão e emoção. 3. ed. São Paulo: HUCITEC, 1999.

SHIRAISHI NETO, Joaquim. Quebradeiras de coco: "babaçu livre" e reservas extrativistas. Veredas do direito, Belo Horizonte, v. 14, n. 28, p. 147-166, 2017.

SOUSA, Maria Sueli Rodrigues de; SANTOS, Joaquim José Ferreira dos. Territorialidade quilombola e trabalho: relação não dicotômica cultura e natureza. Revista Katálysis, Florianópolis, v. 22, n. 1, p. 201-209, 2019.

VARELLA, Marcelo; DUARTE, Letícia Ayumi; MARTINS, Pedro. "Cartografias sociais e a representação de territorialidades específicas: uma discussão espacial". In: RANDOLPH, Rainer; TAVARES, Hermes M. (orgs.). Política e planejamento regional: uma coletânea. Brasília: Movimento, 2013, p. 172-183.

ZANELATTO, Vera Lúcia C. A caça à baleia na Armação de Imbituba e no Sul Catarinense. Monografia - História/UNESC. Criciúma, 1992.

ZUMBLICK, Walter. Teresa Cristina: a ferrovia do carvão. Florianópolis: Ed. da UFSC, 1987.

\section{NOTAS DE AUTOR}

\section{CONTRIBUIÇÃO DE AUTORIA}

Elisa Quint de Souza de Oliveira - Concepção. Coleta de dados. Análise de dados. Elaboração do manuscrito, revisão e aprovação da versão final do trabalho

Isa de Oliveira Rocha - Concepção e elaboração do manuscrito. Análise de dados. Participação ativa da discussão dos resultados. Revisão e aprovação da versão final do trabalho.

Pedro Martins Concepção e elaboração do manuscrito. Análise de dados. Participação ativa da discussão dos resultados. Revisão e aprovação da versão final do trabalho. 


\section{CONSENTIMENTO DE USO DE IMAGEM}

Não se aplica.

\section{APROVAÇÃO DE COMITÊ DE ÉTICA EM PESQUISA}

Não se aplica.

\section{CONFLITO DE INTERESSES}

Não se aplica.

\section{LICENÇA DE USO}

Este artigo está licenciado sob a Licença Creative Commons CC-BY. Com essa licença você pode compartilhar, adaptar, criar para qualquer fim, desde que atribua a autoria da obra.

\section{HISTÓRICO}

Recebido em: 17-09-2019

Aprovado em: 01-02-2021 